\title{
Role of Intravenous Ferric Carboxy-maltose in Pregnant Women with Iron Deficiency Anaemia
}

\author{
Vineet Mishra, ${ }^{1}$ Khusaili Gandhi, ${ }^{1}$ Priyankur Roy, ${ }^{1}$ Shaheen Hokabaj, ${ }^{1}$ Kunur N Shah, ${ }^{1}$ \\ ${ }^{1}$ Department of Obstetrics and Gynecology, Institute for Kidney Disease and Research Centre, BJ Medical \\ College, Asarwa, Ahemdabad, India.
}

\begin{abstract}
Background: Iron deficiency is a common nutritional deficiency amongst women of childbearing age. Peri-partum iron deficiency anaemia is associated with significant maternal, foetal and infant morbidity. Current options for treatment include oral iron, which can be ineffective and poorly tolerated, and red blood cell transfusions, which carry an inherent risk and should be avoided. Ferric carboxymaltose is a modern treatment option. The study was designed to assess the safety and efficacy of intravenous ferric carboxymaltose for correction of iron deficiency anaemia in pregnant women.

Methods: A prospective study was conducted at Institute of Kidney Disease and Research Centre, Ahmedabad from January 2014 to December 2016. Antenatal women (108) with iron deficiency anaemia were the study subjects. Sociodemographic profile was recorded and anaemia was assessed based on recent haemoglobin reports. Iron deficiency was diagnosed on basis of serum ferritin value. Intravenous ferric carboxymaltose as per total correction dose (maximum $1500 \mathrm{mg}$ ) was administered to all women; the improvement in haemoglobin levels were assessed after 3 weeks of total dose infusion.

Results: Most of the women( $\mathrm{n}=45,41.7 \%)$, were in the age group of 27-30 years. Most of the women $(\mathrm{n}=64$, $59.3 \%$ ) had moderate anaemia as per WHO guidelines. Mean haemoglobin levels significantly increased over a period of 3 weeks after Ferric carboxymaltose administrationand no serious life threatening adverse events were observed.

Conclusions: Intravenous ferric carboxymaltose was safe and effective in pregnent women with iron deficiency anaemia.

Keywords: Ferric carboxymaltose; iron; deficiency anaemia; pregnancy.
\end{abstract}

\section{INTRODUCTION}

In India, prevalence of anaemia, especially iron deficiency anaemia (IDA), ranges between $33-89 \% .^{1}$ According to $\mathrm{WHO}$, the prevalence of IDA is about $18 \%$ in developed countries and $35-75 \%$ in developing countries. ${ }^{2}$ India contributes to about 80 per cent of maternal mortality due to anaemia. . $^{3,4}$

A French study, showed depleted iron stores (serum ferritin $<15 \square \mathrm{g} / \mathrm{L}$ ) in one out of five women of childbearing age. ${ }^{5}$ During pregnancy, the need for absorbed iron increases from $0.8 \mathrm{mg} /$ day in the first trimester to $7.5 \mathrm{mg} /$ day in the third trimester. ${ }^{6}$ WHO has classified anaemia into mild $(9-11 \mathrm{gm} \%)$, moderate $(7-9 \mathrm{gm} \%)$ and severe $\left(<7\right.$ gm\%) categories. ${ }^{7}$

Anaemia during pregnancy is associated with increased morbidity and mortality of pregnant women and their foetuses. ${ }^{8}$ IDA has been shown to be associated with an increased risk of premature birth and low birth weight, ${ }^{9}$ pre-eclampsia, ${ }^{10}$ placental abruption and increased peri- partum blood loss, ${ }^{11}$ cardiac failure and death. ${ }^{12,13}$

In pregnant women, oral iron is recommended as firstline treatment for pregnant women with iron deficiency anaemia. ${ }^{14}$ However, oral iron substitution has shown to be insufficient for the treatment of severe IDA and is associated with gastrointestinal side effects. ${ }^{15}$ Guidelines recommend that physicians consider intravenous iron administration in pregnant women with severe IDA, in cases with intolerance to oral iron and insufficient haemoglobin increase after oral iron. ${ }^{16}$

\section{METHODS}

This was an observational study conducted over a period of 3 years (January 2014 to December 2016). A total of 108 women attending the antenatal clinic at the Institute of Kidney Disease and Research Centre, Ahmedabad were recruited for the study.

This study was done to assess anaemia in antenatal women and to administertotal correction dose (500- 
$1500 \mathrm{mg}$ ) of intravenous ferric carboxymaltose (FCM)as calculated by Ganzoni formula. ${ }^{17}$ The primary aim was to study the efficacy and safety of FCM in the treatment of IDA in antenatal women in a tertiary care centre. After explaining about the requirement of administering FCM, its adverse effects, written informed consent were obtained from all the women and attenders. Ethical guidelines were followed as advised for human studies and an IRC approval was also obtained from the institute.

Women more than 20 years of age, with haemoglobin $\mathrm{Hb}$ levels between $4 \mathrm{gm} \%$ to $11 \mathrm{gm} \%$ and confirmed diagnosis of IDA were included in the study. Women were started with oral iron as is usually done in early weeks of pregnancy, but in case of non-compliance or poor response, they were planned for treatment with injectable iron therapy.Women with haemodynamic instability or having history of allergic reactions to iron therapy previously were excluded from the study.

Iron deficiency was diagnosed on parameters like complete blood count $(\mathrm{CBC})$, peripheral blood smear, packed cell volume $(P C V)$, serum ferritin, serum total iron binding capacity (TIBC) and serum iron. Patients were explained about the drug and possible side effects.

The total required dose of Ferric Carboxy Maltose (FCM) was calculated on the basis of hemoglobin deficit and body weight using Ganzoni formula: ${ }^{17}$

Total iron deficit $(\mathrm{mg})=$ Body weight $(\mathrm{kg}) \times[$ Target $\mathrm{Hb}$ Actual $\mathrm{Hb}(\mathrm{gm} \%)] \times 0.24+$ Depot iron $(\mathrm{mg})$

Depot iron $=15 \mathrm{mg} / \mathrm{kg}$ in case of body weight $<35 \mathrm{~kg}$ and $500 \mathrm{mg}$ in case of weight $>35 \mathrm{~kg}$

A single dose of Intravenous FCM, not exceeding $1500 \mathrm{mg}$ of iron ( $30 \mathrm{ml})$ per day was given. FCM was administered as an infusion diluted in sterile $0.9 \%$ sodium chloride $(\mathrm{NaCl})$ solution. FCM injection, $500 \mathrm{mg}$ can be diluted with $100 \mathrm{ml} \mathrm{NaCl}$ and administered over 6 minutes. Doses between $1000 \mathrm{mg}$ and $1500 \mathrm{mg}$ require dilution with $250 \mathrm{ml} \mathrm{NaCl}$ and an administration time of 15 minutes. The drug was administered under direct supervision of doctors as well as paramedical staffs and infusion was immediately stopped in case of any side effects. The patients were followed up after three weeks of total dose infusion to assess the status of iron stores and increase in hemoglobin using same parameters as previously mentioned.

\section{RESULTS}

A total of 108 antenatal women who were booked at our tertiary care hospital were included in the study.
Most of the women were aged between 27-30 years of age $(n=45,41.7 \%)$ [Table 1]. Majority of them were multigravidas $(62.9 \%)$ while the rest, $37.1 \%$ women were primigravidas. Most of the women had moderate anaemia (59.3\%), whereas $13.8 \%$ women had severe anaemia and they also responded well to intravenous FCM therapy (Table 2).

Table 1. Distribution according to age $(n=108)$

\begin{tabular}{|lr|}
\hline Age (years) & No. of women \\
\hline $19-22$ & $10(9.3 \%)$ \\
\hline $23-26$ & $31(28.7 \%)$ \\
$27-30$ & $45(41.7 \%)$ \\
\hline $31-34$ & $13(12.0 \%)$ \\
\hline $35-38$ & $9(8.3 \%)$ \\
\hline
\end{tabular}

\section{Table 2. Distribution according to degree of anaemia $(n=108)$.}

$\begin{array}{lr}\text { Degree of anaemia } & \text { No. of women } \\ \text { Mild } & 29(26.9 \%) \\ \text { Moderate } & 64(59.3 \%) \\ \text { Severe } & 15(13.8 \%)\end{array}$

As calculated according to Ganzoni formula, most of the women $(45.4 \%)$ required 3 vials of intravenous FCM, for total correction dose infusion [Table3]. There was a significant improvement in haemoglobin levels over a period of 3 weeks from mean haemoglobin of $9.07 \pm 1.15$ to $11.17 \pm 2.34$. Other parameters like TIBC, Ferritin and Iron also suggested a significant improvement after FCM administration. Table 4 shows the efficacy of the drug in the management of IDA in our study population.

\section{Table 3. Number of FCM vials administered $(\mathbf{n}=$} 108).

\begin{tabular}{|lr|}
\hline No. of vials & No. of women \\
\hline 1 & $19(17.6 \%)$ \\
\hline 2 & $40(37.0 \%)$ \\
\hline 3 & $49(45.4 \%)$ \\
\hline
\end{tabular}

Table 4. Laboratory parameters before and after FCM administration.

\begin{tabular}{|l|r|r|r|}
\hline Variables & Pre-values & \multicolumn{1}{l}{ Post-values } & p-value \\
\hline Haemoglobin & $9.07 \pm 1.15$ & $11.17 \pm 2.34$ & $<0.001$ \\
\hline PCV & $28.16 \pm 3.24$ & $35.61 \pm 21.38$ & $<0.001$ \\
\hline TIBC & $353.02 \pm 104.73$ & $234.42 \pm 60.63$ & $<0.001$ \\
\hline Ferritin & $22.73 \pm 29.55$ & $190.45 \pm 115.43$ & $<0.001$ \\
\hline Iron & $53.60 \pm 38.37$ & $121.53 \pm 60.41$ & $<0.001$ \\
\hline
\end{tabular}


No serious life threatening adverse events were reported in any of the women. Three women had local reactions like itching and irritation at local site while another 5 women, reported systemic reactions in the form of giddiness, headache and nausea (Table 5). The sense of wellbeing also improved in all women on follow up, except for 5 woman who felt that she was not being adequately treated as oral iron medications were stopped after FCM administration.

\section{Table 5. Adverse reactions of FCM $(n=108)$.}

$\begin{array}{lr}\text { Description } & \text { No. of women } \\ \text { Local reactions } & 3(2.8 \%) \\ \text { Systemic reactions } & 5(4.6 \%) \\ \text { Total adverse reactions } & 8(7.4 \%)\end{array}$

\section{DISCUSSION}

This observational study investigated the efficacy and safety of FCM during pregnancy. FCM treatment efficiently increased haemoglobin levels and also improved the stores. There were no serious hypersensitivity reactions, anaphylactic reactions or other adverse events reported with FCM treatment. Most women received a single dose of $1500 \mathrm{mg}$ iron which is in line with the institution's protocol. No woman in our study required more than one FCM administration due to persistent anaemia. This practice of single dose administration is facilitated by the greater stability of the FCM complex compared to less stable intravenous iron compounds such as ferric gluconate and iron sucrose that require multiple administrations of lower doses. Only few randomized controlled studies on the use of FCM during pregnancy are present, though its safety has been proven beyond doubt in postnatal and gynaecological women. ${ }^{18,19}$

In this study, it was observed that pregnant women responded wonderfully to intravenous FCM. Important contributing factors responsible for high incidence of anaemia in our country include early marriage, teenage pregnancy, multiple pregnancies, less birth spacing, low iron and folic acid intake and high incidence of worm infections in Indian population. ${ }^{20}$ As the number of pregnancies increase the risk of anaemia and its severity goes on increasing, if adequate spacing is not maintained.

The prevalence of IDA in primigravidas was $37.1 \%$ and in multigravidas was $62.9 \%$. The reason for this finding could be frequent pregnancies and lack of optimum spacing between two births, leading to exhaustion of already scarce iron stores. In a prospective study, intravenous FCM infusion significantly increased haemoglobin values $(p<0.01)$ above baseline levels in all women. Increased haemoglobin values were observed at 3 and 6 weeks post infusion and up to 8 weeks post-infusion. Ferritin values also increased significantly after the infusion. ${ }^{21}$ Earlier starting of iron supplementation in these patients, seems to be the most important strategy. ${ }^{22}$

David et al, Evstatiev et al and Iftikhar et $\mathrm{al}^{23-25}$ proved that FCM was well tolerated and had better compliance than other iron preparations. The results of our study were consistent with the above mentioned trials. FCM has been shown to be an effective option in the treatment of IDA in multiple studies and it also improves the quality of life. ${ }^{26}$

There was an increase in mean hemoglobin levels with replenishment of iron stores and clinical improvement after FCM administration. FCM was well tolerated and was associated with few local and mild systemic reactions but no serious life threatening allergic reactions were reported. Thus, FCM is a safe and an effective treatment option for IDA.

\section{CONCLUSIONS}

FCM is a safe and an effective treatment option for IDA of various etiologies. This intervention was instrumental in treating women with significant antenatal anaemia, resulting in haemoglobin values higher than their pretreatment values.

\section{REFERENCES}

1. Kaur IP, KaurS. A comparison of nutritional profile and prevalence of anaemia among rural girls and boys. Journal of Exercise Science and Physiotherapy.2011; 7(1): 11-8. $\underline{\text { Link }}$

2. Kaur M,Kochar GK. Burden of anaemia in rural and urban Jat women in Haryana state, India. Mal J Nutr. 2009;15(2):175-84. Link

3. Kaur K. Anaemia - 'A silent killer' among women in India: present scenario. Euro J Zool Res. 2014;3(1):32-6.Link

4. Kalaivani K. Prevalence and consequences of anaemia in pregnancy. Indian J Med Res. 2009;130:627-33.Link

5. Galan P, Yoon HC, Preziosi P, Viteri F, Valeix P, Fieux B, Briancon S, Malvy D, Roussel AM, Favier A, Hercberg S. Determining factors in the iron status of adult women in the SU. VI. MAX study. European journal of clinical nutrition. 1998;52(6):383-8. Link 
6. Milman N, Bergholt T, Byg KE, Eriksen L, Graudal N. Iron status and iron balance during pregnancy. A critical reappraisal of iron supplementation. Acta obstetricia et gynecologica Scandinavica. 1999 1;78(9):749-57.Link

7. Allen LH. Anaemia and iron deficiency: Effects on pregnancy outcome. Am J of Clin Nutr. 2000; 71(5): 1280s-4s. [MEDLINE]

8. Murphy JF, Newcombe RG, O'riordan J, Coles EC, Pearson JF. Relation of haemoglobin levels in first and second trimesters to outcome of pregnancy. The Lancet. 1986;327(8488):992-5. Link

9. Scholl TO. Iron status during pregnancy: setting the stage for mother and infant. Am J of Clin Nutr. 2005;81(5): 1218s-22s. Link

10. Milman N, Agger AO, Nielsen OJ. Iron status markersand serum erythropoietin in 120 mothers and newborn infants -Effect of iron supplementation in normal pregnancy. Acta Obstetriciaet Gynecologica Scandinavica. 1994;73(3):200-4. Link

11. Arnold DL, Williams MA, Miller RS, Qiu C, Sorensen TK. Iron deficiency anaemia, cigarette smoking and risk of abruptio placentae.JOGR. 2009;35(3):446-52.Link

12. Reveiz L,Gyte GM, Cuervo LG, Casasbuenas A. Treatmentsfor iron-deficiency anaemia in pregnancy.2011; Cochrane Database of Systematic Reviews, no. 10, Article ID CD003094. Link

13. Viteri FE. The consequences of iron deficiency and anaemiain pregnancy onmaternal health, the foetus and the infant.SCN News. 1994;11:14-8.

14. Villar J,Merialdi M, Gulmezoglu AM. Nutritional interventions during pregnancy for the prevention or treatment of maternal morbidity and preterm delivery: An overview of randomized controlled trials. J Nutr. 2003;133(5):1606s-25s.Link

15. Breymann C, Honegger C, Holzgreve W, Surbek D. Diagnosis and treatment of iron-deficiency anaemia during pregnancy and postpartum. Arch Gynecol Obstet. 2010; 282(5): 577-80. Link

16. Milman N. Pre-partum anaemia: prevention and treatment. Ann Hematol. 2008; 87(12): 949-59. Link

17. Keeler BD, Simpson JA, Ng S, Acheson AG. The feasibility and clinical efficacy of intravenous iron administration for preoperative anaemia in patients with colorectal cancer. Colorectal Dis. 2014;16(10):794-800. Link

18. Gautam VP, Bansal Y, Taneja DK, Saha R. Prevalence of anaemia amongst pregnant women and its sociodemographic associates in a rural area of Delhi. Indian J
Com Med. 2010;27(4):157-60. Link

19. Panghal R, Boora P. Prevalence of anaemia among pregnant women of low income group of Hisar district of Haryana. Journal of Dairying Foods and Home Science. 2010;29(2):144-7. Link

20. Charytan C, Bernardo M, Koch T, Butcher A, Morris D, Bregman DB. Intravenous FCM versus standard medical care in the treatment of iron deficiency anaemia in patients with chronic kidney disease: A randomized, activecontrolled, multicentre study. Nephrol Dial Transplant. 2013;28:953-64. Link

21. Froessler B, Collingwood J, Hodyl NA, Dekker G. Intravenous ferric carboxymaltose for anaemia in pregnancy. BMC Pregnancy Childbirth. 2014 25;14(1):115. Link

22. Wolf M, Koch TA, Bregman DB. Effects of iron deficiency anaemia and its treatment on fibroblast growth factor 23 and phosphate homeostasis in women. J Bone Min Res. 2013;28(8):1793-803. Link

23. David BB, Lawrence TG. Experience with intravenous FCM in patients with iron deficiency anaemia. Ther Adv Hematol. 2014;5(2):48-60. Link

24. Evstatiev, Marteau, Iqbal T, Khalif IL, Stein J, Bokemeyer B. FERGI Study Group: A randomized controlled trial on ferric carboxy maltose for iron deficiency anaemia in inflammatory bowel disease. Gastroenterology. 2011;141(3):846-53. Link

25. Iftikhar H, Jessica B, Angelia B, Todd A, Andy H, David BB. Direct comparison of the safety and efficacy of ferric carboxymaltose versus iron dextran in patients with IDA. Anaemia. 2013; Article ID 169107. Link

26. Anker SD, Comin Colet J, Filippatos G, Willenheimer R, Dickstein K, Drexler H, Lüscher TF, Bart B, Banasiak W, Niegowska J, Kirwan BA. Ferric carboxymaltose in patients with heart failure and iron deficiency. N Engl J Med. 2009;361(25):2436-48.Link 